\title{
Object-based visual attention with endogenous orienting
}

\author{
RICHARD A. ABRAMS and MARK B. LAW \\ Washington University, St. Louis, Missouri
}

\begin{abstract}
In a series of experiments, we examined covert orienting using endogenous cuing, in which attention is voluntarily directed toward a peripheral location. In one experiment, subjects were cued to attend to one end of an oblong object. They then detected targets on the cued object or elsewhere. In another experiment, subjects provided judgments of the relative temporal order of two flashes after their attention had moved endogenously. In a third experiment, subjects were directed to attend to an empty spatial location and subsequently discriminated features of objects that appeared at or near the locus of attention. In each of these situations, attentional orienting was object based, in the sense that nonattended locations that were on the cued object had an advantage over nonattended locations that were not on the object. The results are discussed in terms of their implications for object-based representations and the differences between exogenous and endogenous orienting of attention.
\end{abstract}

Our visual world is a complex and cluttered one, containing more stimulation than we can process at any one time. To make sense of it all, we can selectively attend to some objects in a scene at the expense of others, even within a single fixation. The efficiency with which we can selectively attend, however, is affected by a number of factors, including the locus of attentional control (exogenous or endogenous), the representational basis of selection (object based or spatial), and the features of the stimuli and the task at hand. Our present goal is to learn more about how such attentional selection takes place and about the ways in which the selection may be guided by the perceptual objects that are present in a scene. In particular, we focus here on object-based, endogenous selection. We begin by considering two different modes of attentional control.

\section{ENDOGENOUS VERSUS EXOGENOUS ORIENTING}

Researchers have identified two ways in which such attentional selection can be accomplished. Under exogenous (or stimulus-driven) orienting, attention is attracted to a location in the visual field as a result of some external stimulation arising from that location, such as a flash of light (Posner, 1980) or the appearance of a new object (Oonk \& Abrams, 1998; Yantis \& Hillstrom, 1994). With endogenous (or goal-directed) orienting, an observer can

Portions of this research were reported at the November 1997 Annual Meeting of the Psychonomic Society (Law \& Abrams, 1997). We thank Dale Dagenbach, Art Kramer, Steve Yantis, and an anonymous reviewer for interesting and helpful comments on an earlier version of the manuscript. The research was supported by Grant MH45145 from the National Institutes of Health. Correspondence concerning this article should be addressed to R. A. Abrams, Psychology Department, Washington University, St. Louis, MO 63130 (e-mail: rabrams@artsci.wustl. edu). simply choose to attend to one location or another, perhaps as a result of some probabilistic information available about the likely location of an upcoming stimulus (Posner, 1980). Under both exogenous and endogenous orienting, observers enjoy benefits at the attended location, such as reduced latency and increased accuracy in detecting and identifying target stimuli there (see Yantis, 1998, for a recent review).

Despite the apparent similarities, there is reason to believe that endogenous and exogenous orienting may actually be accomplished by different mechanisms. First, some researchers have reported a different time course for endogenous and exogenous orienting, suggesting that different means are used to accomplish the movement of attentional resources (Jonides, 1981; Müller \& Rabbitt, 1989). And although some have found additive effects of endogenous and exogenous orienting on response times, consistent with two separate and independent mechanisms (Riggio \& Kirsner, 1997), others have reported that exogenous cues can override endogenous ones under some, but not all, circumstances (Müller \& Rabbitt, 1989; Yantis \& Jonides, 1990). In addition to the differences in the mode of transport (Klein, 1994) of the attentional resources, there appear also to be differences in the transported resources themselves. For example, Klein and colleagues have found differences in the extent to which the benefits of endogenous and exogenous cues interact with other factors, such as stimulus-response expectancies or the need for a feature versus a conjunction visual search (Briand \& Klein, 1987; Klein, 1994; Klein \& Hansen, 1990). Finally, others have shown that inhibition of return exists after attention is drawn to the periphery via a flash, but not after attention is directed endogenously by a symbolic central cue (Posner \& Cohen, 1984; Rafal, Calabresi, Brennan, \& Sciolto, 1989). ${ }^{1}$

Taken together, the numerous differences between endogenous and exogenous orienting suggest that they rep- 
resent two very different attentional mechanisms. In the present paper, we are concerned with one additional potential difference between the two types of orienting: the nature of the mental representation that underlies the selection. In particular, when attentional mechanisms are employed to select a portion of the world for further processing, is selection made on the basis of the spatial location to be further analyzed (a space-based representational system), or is selection made on the basis of the perceptual objects to be further processed (an objectbased representation)?

\section{OBJECT-BASED ATTENTIONAL SELECTION}

A considerable amount of evidence already exists that demonstrates that visual attention can be object based, at least under some conditions. Duncan (1984) provided one of the first reports of such a possibility. He had subjects report two attributes from a display that contained two overlapping objects. Subjects were more accurate in reporting two attributes from one object than in reporting one attribute from each of the two objects, even though the distance between attributes was the same for within- and between-object attribute pairs. Duncan's results, which have been confirmed and extended (Vecera \& Farah, 1994; but see Kramer, Weber, \& Watson, 1997), suggest that selection may occur at a level of the visual system at which information is available about the objects that are present but not necessarily about the precise locations of the objects.

There are also a number of other situations in which objects have been shown to play an important role in visual selection. For example, Baylis and Driver (1993; but see Lavie \& Driver, 1996) found that subjects were faster to compare two points on one object than one point on each of two objects, even though the one- or the twoobject condition was determined by an instructional set. Tipper, Driver, and Weaver (1991) showed that inhibition of return (thought to be at least partly an attentional phenomenon) will move with an object as it moves through the environment. Kahneman, Treisman, and Gibbs (1992) showed an object-specific preview benefit for the identification of letters. And different types of perceptual grouping and segmentation processes have been shown to affect the ability to selectively attend to part of a display (Driver \& Baylis, 1989; Kramer \& Jacobson, 1991). In each of these cases, selective attention was guided not merely by the spatial position of elements in the display, but by the extent to which the elements were or were not perceived to be parts of specific objects.

For present purposes, we were particularly interested in a study reported by Egly, Driver, and Rafal (1994). They had subjects attend to one end of a rectangular object and then detect a probe flash, either in the attended object or in another, nearby object. The subjects were faster to detect the probe when it appeared at the uncued end of the cued object than when it was presented in a different object, even though both locations were equidistant from fixation and from the location that had been cued. The former location seemed to enjoy some attentional advantage because it was located on the object that had been cued. ${ }^{2}$ The result is almost as if the benefit of attention had spread or radiated from the cued location throughout the object, and for this reason, we refer to the phenomenon as a radiation of attention, in part to distinguish it from other demonstrations of object-based orienting.

The Egly et al. (1994) results show that attentional selection can access object-based representations; yet, the results were obtained using peripheral cues to attract the subject's attention. Thus, exogenous orienting mechanisms are assumed to have been engaged. (Because the cues were informative with respect to the subsequent target location, endogenous orienting was also involved.) However, as was noted earlier, it is also possible for people to move attention purely endogenously. Because of the numerous differences between endogenous and exogenous orienting, we cannot yet be certain that endogenous orienting will also lead to an object-based radiation of attention. Indeed, determining whether it can could be very informative with respect to differences between exogenous and endogenous orienting. The goal of the present project is to answer that question. Specifically, does endogenous attentional orienting produce an object-based radiation of attention? If it does, that would suggest that endogenous orienting mechanisms access object representations, as exogenous mechanisms are known to.

In addition to the empirical dissociation between goaldirected and stimulus-driven orienting, there are also a number of theoretical reasons to determine the extent to which object-based radiation of attention occurs under each type of orienting. For example, Müller and Rabbitt (1989) concluded that peripheral orienting and central orienting involve two distinct mechanisms that each serve the same limited-capacity attentional system. However, if one type of orienting (e.g., via a peripheral cue) can lead to object-based radiation of attention but another type of orienting (e.g., purely endogenous) cannot, the notion of a common attentional system may require reassessment. In particular, it might be necessary to posit two distinct types of attentional systems: one that encodes perceptual objects and is served by stimulus-driven orienting mechanisms, and one served by goal-directed orienting mechanisms that is not object based. An alternative to such a dual-attentional-systems possibility might require that different orienting mechanisms have access to different types of attentional representations. However, it remains to be seen whether such mechanisms would be necessary and precisely how, or if, such a scheme could be implemented.

Several other recent models of attentional mechanisms appear to have objectness as an integral part of their workings, although the models do not specifically address the sort of task typically used to demonstrate radiation of attention. For example, Logan's (1996) model uses an activation map of a scene to guide attentional selection. In his model, the value of a threshold determines 
whether nearby items are or are not considered to be in the same perceptual group. If attentional radiation is to occur with peripheral cuing, but not with purely endogenous orienting, the thresholds would presumably need to be different in those two situations. ${ }^{3}$

Similarly, Wolfe's (1994) model of visual search also proposes an activation map that is used to guide attentional selection. Both bottom-up and top-down factors are thought to influence the activation on the map. Radiation of attention might be explained in such a scheme by a mechanism that boosts the activation for items that are grouped together. Of course, if radiation of attention occurs with peripheral cuing but not with central cues, such enhanced activation for parts of an object would have to operate some of the time (i.e., with peripheral cues) but not other times (i.e., with purely endogenous orienting).

Thus, existing models of attentional selection could be extended to apply to a situation in which radiation of attention might occur. Importantly, additional constraints would be needed if it was found that radiation of attention occurred in some situations but not in others. Thus, determining when radiation of attention does and does not occur could have important implications for such models and for an understanding of the differences between peripheral and central cuing more generally.

There has already been some work on this topic. Neely and Dagenbach (1996), Dagenbach, Goolsby, Neely, and Dudziak (1997), and Macquistan (1997) have all reported failures to find object-based radiation of attention in a paradigm similar to that of Egly et al. (1994), but with endogenous attention cues, even though these researchers were able to replicate the Egly et al. result with exogenous cues. Because the implications for visual selection are potentially so important, we thought it worthwhile to attempt to confirm their findings. To anticipate our results, we found clear evidence for object-based attentional radiation of attention with endogenous cues in the Egly et al. paradigm and also in two other, very different sorts of tasks. A detailed discussion of the earlier failures to find such effects, noted above, will be presented after we report our findings.

\section{OVERVIEW OF THE EXPERIMENTS}

In Experiment 1, we replicated the initial Egly et al. (1994) result, using the usual informative peripheral cues, confirming the finding of object-based radiation of attention in that situation. In Experiment 2, we conducted an experiment using the same paradigm but with purely endogenous cues for orienting attention. That experiment showed that endogenous orienting can also lead to object-based radiation of attention. In Experiment 3, we used temporal order judgments to assess attentional allocation and again found evidence for object-based selection with endogenous orienting. Experiment 4 yielded results from a new paradigm, in which subjects judged attributes of briefly presented objects. There, too, en- dogenous attention was object based. Finally, in Experiments 5,6 , and 7 , we addressed the discrepancy between our conclusion and those of Macquistan (1997), Neely and Dagenbach (1996), and Dagenbach et al. (1997). In Experiment 5, we eliminated an alternative explanation that attributes the different pattern of results to temporal uncertainty regarding the presentation of the target. In Experiment 6, we ruled out an explanation based on differences in the eye movements that the subjects produced. And in Experiment 7, we eliminated an alternative based on differential stimulus probabilities. In each of these latter three experiments, despite the changes made, we continued to find support for the presence of object-based radiation of attention with purely endogenous selection.

\section{EXPERIMENT 1}

We began with a replication of Egly et al.'s (1994) study. The subjects had their attention attracted to one end of a rectangular object by a peripheral flash. A probe was then presented in the cued or the uncued end of the cued object or in another rectangular object that had been present on the display. The subject's task was to simply press a key upon detection of the probe flash.

\section{Method}

Subjects. Fifteen undergraduates participated as paid volunteers in a single, 1 -h session. They all had normal or corrected-to-normal vision, were naive as to the purposes of the experiment, and received $\$ 5$ for their participation.

Procedure and Stimuli. Testing was conducted in a dimly lit, sound-attenuated room. The subjects were seated in front of a computer monitor, and their heads were steadied with a chinrest. The sequence of events during a trial is shown in Figure 1 and was as follows. At the beginning of each trial, the fixation display was shown for $1,000 \mathrm{msec}$. This display consisted of a central fixation plus, which subtended $1.0^{\circ} \times 1.0^{\circ}$, and two rectangles, each of which subtended $10^{\circ} \times 3.3^{\circ}$, with a gray border $0.4^{\circ}$ thick. The rectangles were arranged so that they just fit inside an imaginary $10.0^{\circ}$ square. This imaginary square was oriented at $45^{\circ}$ from the vertical. ${ }^{4}$ All four rectangle ends were the same distance from fixation.

Next, one of the four rectangle ends was cued by changing the gray border along one end of a rectangle (and $3.3^{\circ}$ along each side) to white. The cue remained visible for $100 \mathrm{msec}$ and was then removed. Next, $200 \mathrm{msec}$ after the cue was removed, a target was presented in one of the three rectangle ends that were closest to the cued end. The 300-msec cue-target interval here is the same as that used by Egly et al. (1994). The target was a gray $1.8^{\circ}$ square centered in one end of a rectangle. In the cued condition, the target appeared in the end of the rectangle that had been cued. In the uncued sameobject condition, the target also appeared in the rectangle that had been cued, but at the opposite end. In the uncued different-object condition, the target appeared in the rectangle that had not been cued (in the end closest to the cue). Note that each of the two uncued locations were equidistant from fixation and from the location that had been cued. No targets were presented in the rectangle end diagonally opposite to the cue (but see Experiment 7). The target remained visible until the subject responded.

The subject's task was to press the spacebar on the computer keyboard as soon as he or she detected the appearance of the target. On catch trials, in which no target was presented, the subjects were instructed not to make a response. At the end of the trial, a blank screen 


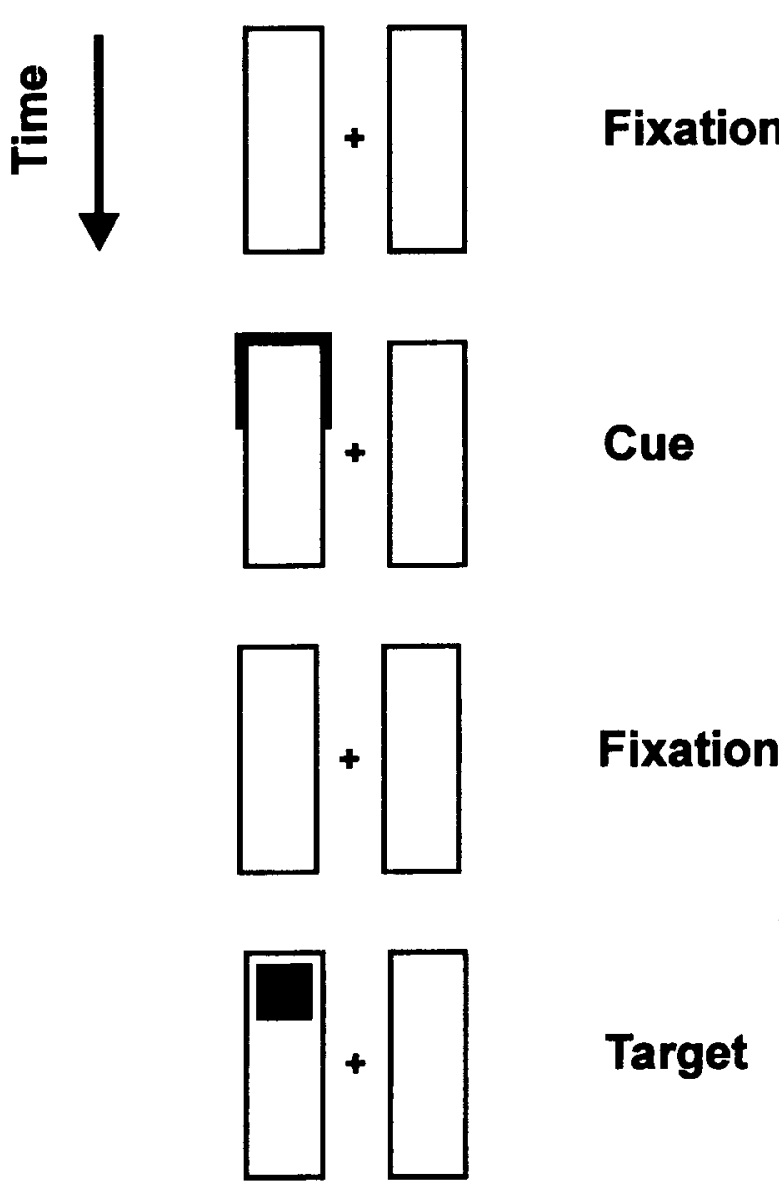

Figure 1. The sequence of events during a trial in Experiments $1,2,5,6$, and 7. In Experiment 1, the display was oriented at $45^{\circ}$ from the vertical. In all the experiments, the actual stimuli were white against a black background.

was displayed for $1,000 \mathrm{msec}$, and then the next trial began. The subjects were provided with performance feedback and an opportunity to take a short rest after every 40 trials.

Design. At the beginning of each session, a practice block of 8 trials was presented; these trials were randomly selected from among the possible conditions. Eight experimental blocks, each comprising 40 trials, followed the practice block. Of these 40 trials, $8(20 \%)$ were catch trials on which no target was presented. Of the trials that had targets, 24 were cued, 4 were uncued same-object trials, and 4 were uncued different-object trials. Therefore, of the trials with targets, the cue accurately predicted the location of the target $75 \%$ of the time. This is the same as the cue validity used by Egly et al. (1994).

\section{Results and Discussion}

Means of the median reaction times for the cued, uncued same-object, and uncued different-object conditions are shown in the top panel of Figure 2.5 The subjects were fastest to detect probes at the cued location, next fastest at the uncued location in the same object, and slowest at the uncued location in the different object $[F(2,28)=11.4, p<.001]$. Considering only the two un- cued conditions, the object advantage was $10.1 \mathrm{msec}$, with subjects faster to detect the probe when it appeared at the uncued end of the cued object (uncued same-object) than when it appeared on the other, uncued object [uncued different-object; $t(14)=2.7, p<.05]$. The subjects made a premature response (latency less than $150 \mathrm{msec}$ ), a late response (latency greater than $1,500 \mathrm{msec}$ ), or a false alarm on fewer than $4 \%$ of the trials. Errors were not analyzed further.

Thus, the present results replicate the finding of objectbased radiation of attention reported by Egly et al. (1994). We now turn to an extension of that result, using purely endogenous attentional cues.

\section{EXPERIMENT 2}

In Experiment 1 and in Egly et al. (1994), the subjects' attention was initially directed to one end of one of the objects, using a peripheral flash. Hence, exogenous stimulusdriven attentional mechanisms were assumed to have been engaged. As was indicated by Macquistan (1997), because the cue also was predictive of the target location in the Egly et al. (1994) study (and in our Experiment 1), it is presumed to have had endogenous qualities as well. That is, the subjects are assumed to have been able to orient to the cued location by virtue of the information conveyed by the cue regarding target probability. Furthermore, the 300-msec cue-target interval used by Egly et al. and in Experiment 1 was potentially long enough for endogenous orienting to take place (Müller \& Rabbitt, 1989). In the present experiment, we sought to examine object-based radiation of attention, using purely centrally cued, or endogenous, orienting. Because orienting to a purely endogenous cue would be expected to take longer than exogenous orienting, we also included a longer cue-target interval of $900 \mathrm{msec}$, in addition to the 300 - $\mathrm{msec}$ interval studied in Experiment 1.

\section{Method}

Subjects. In return for class credit, 15 undergraduates participated in a single, 1-h session. They all had normal or corrected-tonormal vision and were naive as to the purposes of the experiment. None of the subjects had participated in Experiment 1.

Apparatus, Stimuli, and Procedure. Most features of this experiment were identical or similar to those of Experiment 1, with the main difference being that here central arrows were used to direct the subject's attention, rather than peripheral flashes. At the beginning of each trial, the fixation display was shown. This display consisted of a central fixation plus flanked by two $11.4^{\circ} \times 1.7^{\circ}$ rectangles. The rectangles were either vertically oriented and to the left and right of fixation or horizontally oriented and above and below it.

One second after the onset of the display, the fixation plus was replaced with an arrow cue that pointed toward one of the four rectangle ends and remained visible for $300 \mathrm{msec}$. The size of the arrow was such that it would fit inside a $1.1^{\circ} \times 1.0^{\circ}$ box. Either immediately after offset of the arrow (300-msec cue-target interval) or after a 600-msec delay (900-msec cue-target interval), the target, a gray $0.9^{\circ}$ square, was presented in one of the three rectangle ends that were closest to the location designated by the cue. The target remained visible until the subject responded. The subject's task was 


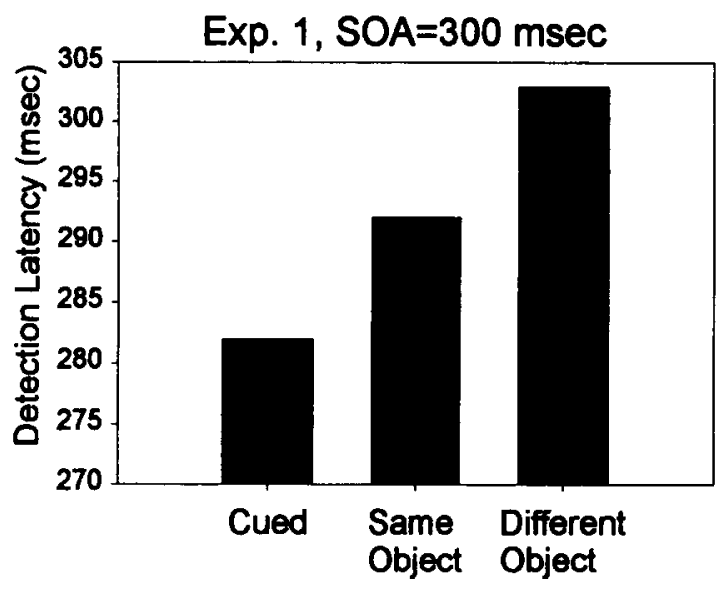

Cue-Target Relationship

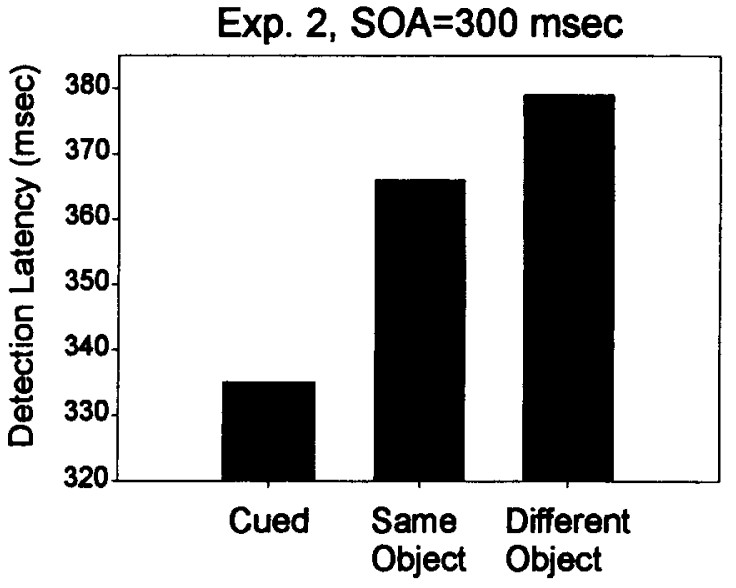

Cue-Target Relationship

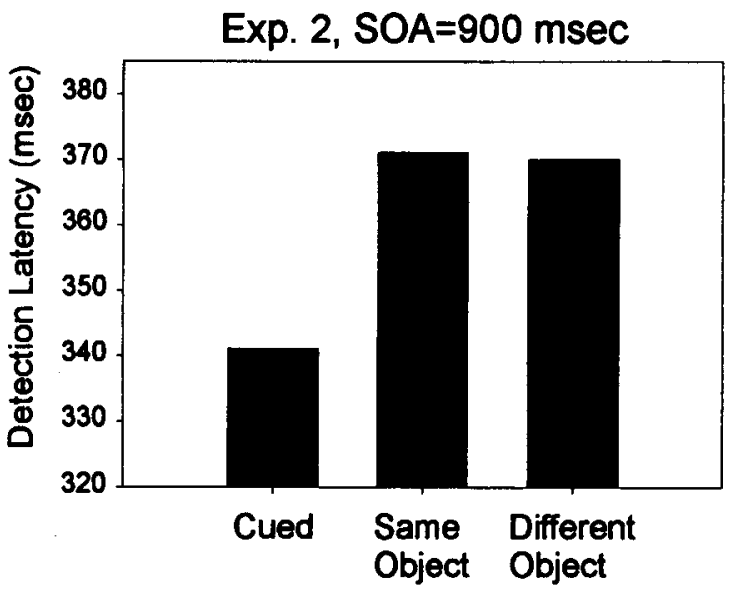

Cue-Target Relationship

Figure 2. The mean reaction times from Experiment 1 (top; with peripheral cues) and Experiment 2 (bottom; with endogenous cues). Faster latencies in the uncued same-object condition (designated "same object" in the figure) than in the uncued different-object condition ("different object") is evidence of an object advantage.

to press a key as soon as he or she detected the appearance of the target. At the end of the trial, a blank screen was displayed for $250 \mathrm{msec}$, and then the next trial began. The subjects were provided with performance feedback and an opportunity to take a short rest after every 48 trials.

Eye movement monitoring. The subjects wore a scleralreflectance eye movement monitor mounted on a spectacles frame (Applied Science Laboratories, Model 210). Output from the eye movement monitor was sampled during the fixation period prior to cue presentation and during the interval between cue presentation and the keypress response, using methods similar to those that we have used previously (Abrams \& Dobkin, 1994). The trial did not begin until the subject's gaze was within $1.5^{\circ}$ of fixation; the trial was excluded from analysis if the subject produced a saccade during the trial.

Design. At the beginning of each session, a practice block of 20 trials was presented; these trials were randomly selected from among the possible conditions. Four experimental blocks, each of which comprised 144 trials, followed the practice block. Of these 144 trials, 112 had targets, and $32(22 \%)$ were catch trials. Of the trials that had targets, $80(71.4 \%)$ were cued trials, 16 uncued sameobject trials, and 16 were uncued different-object trials.

\section{Results}

Means of the median reaction times in each condition are shown in the bottom panel of Figure 2 separately for the 300- and 900-msec cue-target interval conditions. Overall, reaction times differed as a function of cuing condition $[F(2,28)=64.2, p<.001]$. The subjects were fastest to detect the probe at the cued location, indicating that they were attending to the information in the cue. Although cue-target interval did not have a main effect, it did interact with the cuing condition $[F(2,28)=3.5$, $p<.05]$. As can be seen, there was an object advantage 
at the 300-msec cue-target interval but not at the 900 msec interval. The presence of an object effect was confirmed, with $t$ tests, at the 300 -msec cue-target interval $[t(14)=3.3, p<.01 ;$ mean object advantage $=12.2 \mathrm{msec}]$ but not at the 900 -msec cue-target interval $[t(14)=0.25$; mean object advantage $=-1.2]$.

The subjects made an eye movement, a premature response, or a late response on fewer than $2 \%$ of the trials. Errors were not analyzed further.

\section{Discussion}

In the present experiment, we found evidence for objectbased radiation of attention, using endogenous cues. At the 300-msec cue-target interval, the subjects were faster to detect probes that appeared at the uncued end of the cued object than probes that appeared on an uncued object. The object advantage of $12.2 \mathrm{msec}$ was comparable with the 10.3-msec advantage observed in Experiment 1 with exogenous orienting. A comparison between Experiment 1 and the 300 -msec stimulus onset asynchrony (SOA) condition of this experiment showed that the size of the object effect did not differ between experiments $[F(1,28)<1]$. At the 900 -msec cue-target interval, however, the object advantage was no longer present. We believe the absence of an object advantage at the longer cue-target interval may reveal a phenomenon similar to inhibition of return that may have affected responses to the uncued end of the cued object. That is, after attention had radiated throughout the cued object, it then receded and was inhibited in returning there. We have reported just such a result recently (Law \& Abrams, 2000), and there are additional reports of object-based inhibition of return in a slightly different paradigm (Jordan \& Tipper, 1999). Of course, the subjects were able to remain fast when the target appeared at the cued location even at the long SOA, because they knew that it was the most likely target location.

\section{EXPERIMENT 3}

Stelmach and Herdman (1991) have shown that judgments of the relative temporal order of two visual events can provide a good index of the locus of attention. In their study, subjects consistently judged a flash at the locus of attention to have occurred before a simultaneous flash at an unattended location. In the present experiment, we sought to use temporal order judgments to help gauge the extent to which attentional selection accesses objectbased representations and radiates throughout an object. To do that, we obtained temporal order judgments for flashes at uncued locations that either were or were not on objects that had been cued. We studied these judgments, using both endogenous and exogenous attention cues. If attention accesses object-based representations, we would expect the subjects to perceive flashes on cued objects to occur before simultaneous flashes that were not on the
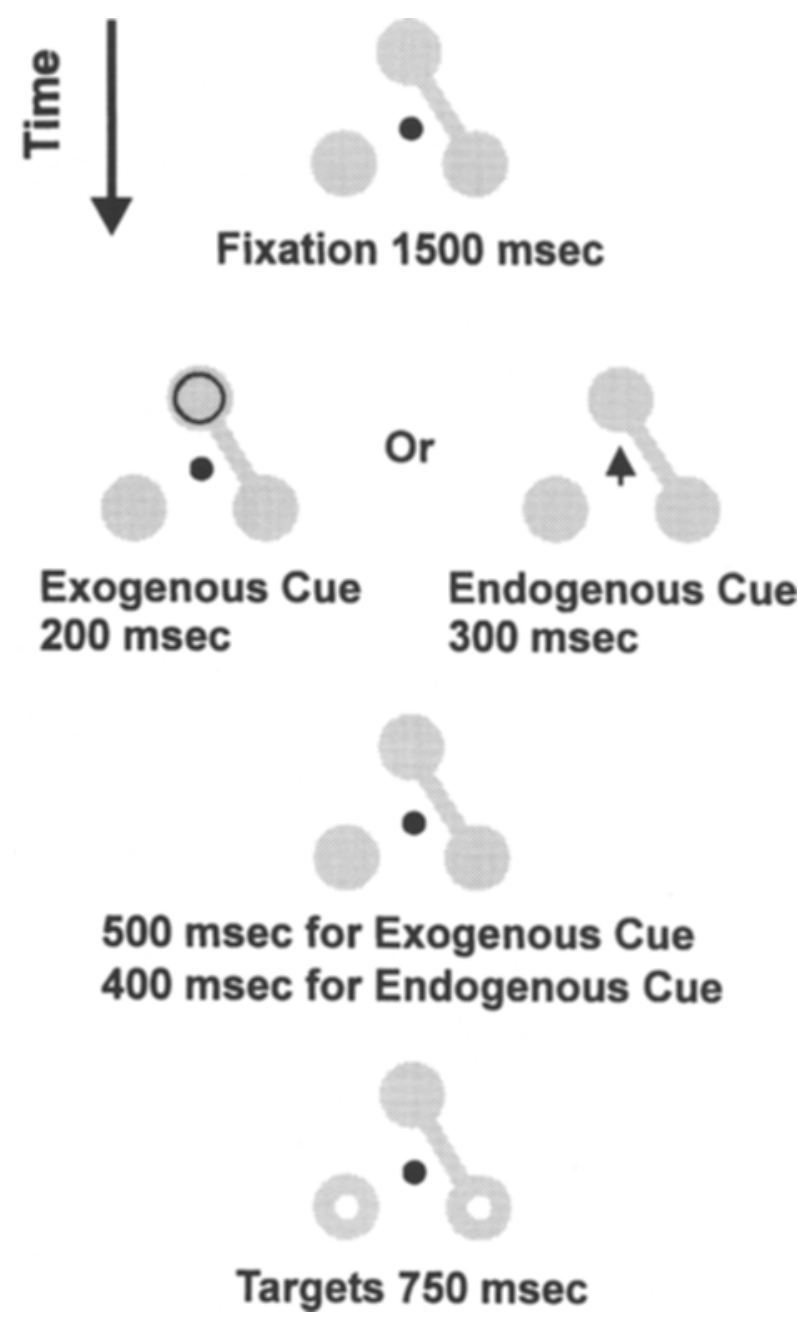

Figure 3. The sequence of events during a trial in Experiment 3. The actual objects used were gray against a black background.

cued object, even when all the flashes were at locations that had not been cued.

\section{Method}

Subjects. In return for class credit, 32 undergraduates each participated in a single, 1 -h session. They all had normal or correctedto-normal vision and were naive as to the purposes of the experiment. None of the subjects had participated in the previous experiments.

Apparatus, Stimuli, and Procedure. The sequence of events in a trial is illustrated in Figure 3. At the beginning of each trial, the subjects viewed a display that consisted of a fixation dot flanked by three gray discs, each $1.0^{\circ}$ in diameter. The discs were each positioned at a different vertex of an imaginary equilateral triangle $\left(8.9^{\circ}\right.$ per side). Two of the discs were connected with a thick gray line so that they appeared to form a barbell and, hence, to be part of the same object. After $1,500 \mathrm{msec}$, a cue was added to the display. In the $e x$ ogenous cue condition, a black ring $\left(0.74^{\circ}\right.$ outside diameter, $0.15^{\circ}$ thick) was presented in one of the three discs for a duration of $200 \mathrm{msec}$, after which it was removed and a delay of $500 \mathrm{msec}$ tran- 


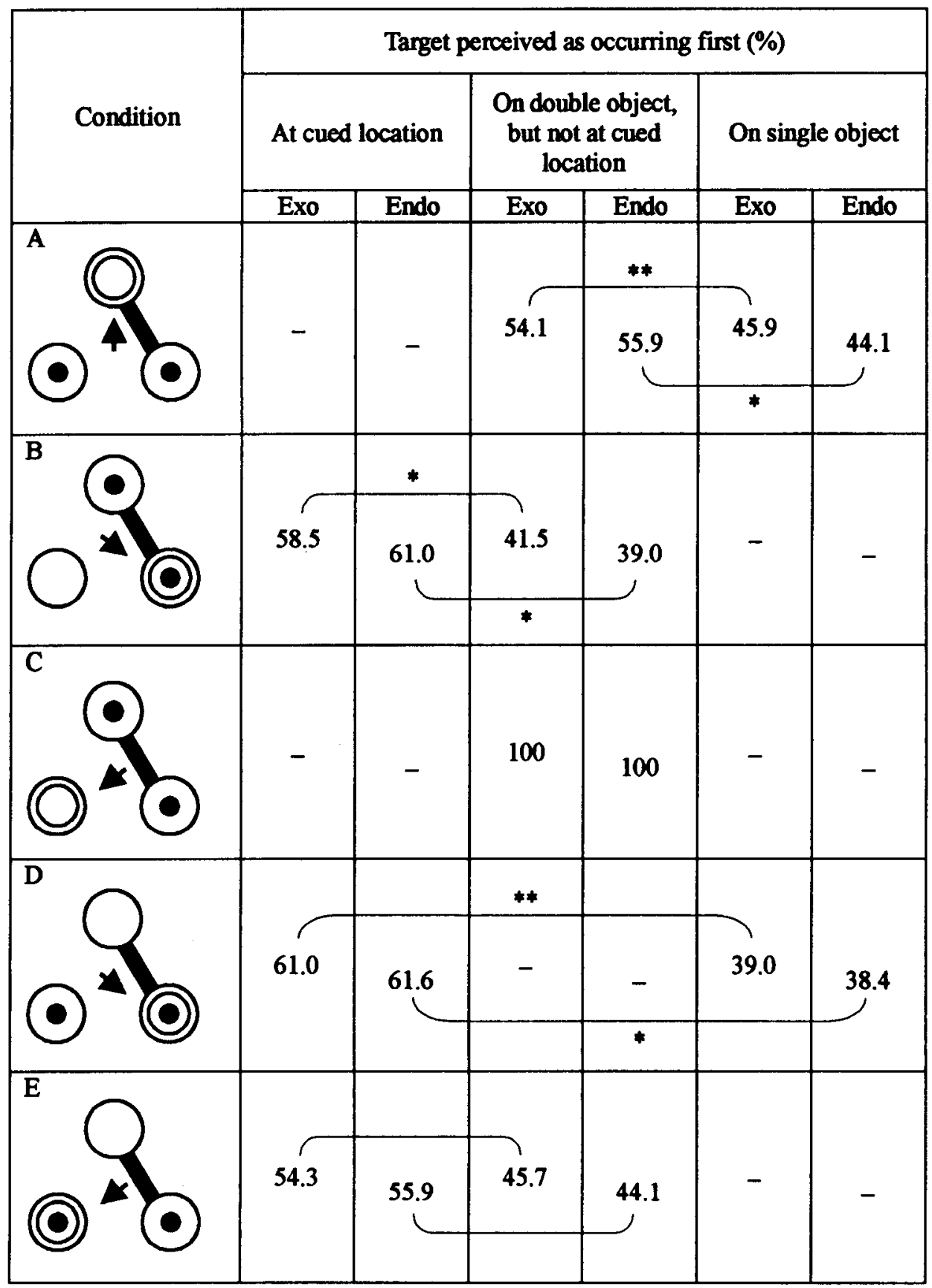

Figure 4. The results from Experiment 3. Entries show the mean percentage of trials on which the indicated stimulus was perceived to have occurred first, for both exogenous (Exo) and endogenous (Endo) cuing conditions. Both types of cues (an arrow and a ring) are indicated in the display shown in the left column, although only one was presented on any one trial. Single object refers to the disc that was not connected to another. Double object refers to the two discs connected together. Braces link the two mutually exclusive and exhaustive response alternatives in each condition. The most important condition is in the first row and is illustrated in panel $A$. There, the subjects judged onsets of two stimuli, neither of which was at the cued location but one of which was on the object that had been cued. Asterisks on a brace indicate that each of the bracketed values differed from $50 \%$ : ${ }^{*} p<.05$, ${ }^{* *} p<.005$.

spired. In the endogenous cue condition, an arrow was presented at fixation, pointing toward one of the three discs. After $300 \mathrm{msec}$, the arrow was removed, and a delay of $400 \mathrm{msec}$ transpired. Next, in each of the cuing conditions, the targets, two white dots $\left(0.01^{\circ} \mathrm{di}-\right.$ ameter), were presented simultaneously at the center of two of the disks and remained visible for the remainder of the trial.
The different possible cue and target locations are shown on the left side of Figure 4. On a given trial, each of the three discs was equally likely to be cued, and the cue was uninformative with respect to the target locations. In the exogenous cue condition, the subjects were told that they could ignore the ring. In the endogenous cue condition, the subjects were told only that the arrow pointed to one 
of the locations that was likely to contain a target dot. Of course, that was always true for any given location, since two of the three locations always contained a target. The different possible combinations of cue and target are shown in the figure. The most important condition is shown in panel $A$, in which neither of the two targets was presented at the location that had been cued, although one of them did appear on the object that had been cued. Note that both exogenous and endogenous cues are illustrated in the figure, although only one type of cue was presented on any one trial.

The subject's task was to indicate the target that was perceived to have been presented first. They did this by using a mouse-controlled pointer that appeared on the display $750 \mathrm{msec}$ after the target had appeared. Between trials, 750 msec elapsed. The subjects were provided with performance feedback and an opportunity to take a short rest after every 40 trials.

Design. There were nine possible combinations of one cued location and two probed locations, given the three disks. Each of these nine distinct trial types was presented seven times in a trial block. On each presentation, the display was shown at a different orientation, randomly selected from 18 orientations that spanned $360^{\circ}$. A practice block of 10 trials preceded 10 experimental blocks, each comprising 63 trials. Cue type (endogenous or exogenous) was a betweensubjects factor, with half of the subjects receiving each type.

\section{Results and Discussion}

The results are shown in Figure 4 separately for endogenous and exogenous cues and for each of the various cue-target combinations. Included in the figure is the percentage of trials on which each of the targets was judged to have been presented first. Two features of these results are noteworthy. First, over all the conditions, targets at cued locations were judged to appear first most of the time $(59.5 \%$ for endogenous cues, $57.9 \%$ for exogenous cues). This shows the expected result of attention's affecting temporal order judgments. Second and more important, in the critical condition shown in panel A (in which neither of the two target locations had been cued), the subjects were more likely to perceive the target on the cued object to have occurred first, as compared with the one at the other location. This result was observed for both exogenous $[54.1 \% ; t(15)=3.8, p<.005]$ and endogenous $[55.9 \% ; t(15)=2.5, p<.05]$ cues. Thus, the temporal order judgments reveal that the subjects were biased to perceive one of two simultaneous events to have occurred first if that event was on the same object to which attention had previously been directed. Importantly, this result was obtained for both exogenously and endogenously directed attention. ${ }^{6}$

\section{EXPERIMENT 4}

Experiments 2 and 3 showed that endogenous attentional orienting can be object based. However, in those experiments, the objects were present on the display in advance of the attentional cue. Thus, the subjects were essentially being cued to attend to part of one of the objects. This may have caused them to employ an objectbased representation when they might not otherwise have done so. However, it is possible to orient one's atten- tion to empty spatial locations and to then examine the subsequent perception of objects presented at or near the locus of attention. In the present experiment, we did just that. We first directed the subjects' attention to an empty peripheral location. We then had them perform a discrimination task in which they judged the size of a gap in a line segment. Importantly, the line segment was often presented some distance away from the presumed locus of attention. However, the line segment formed part of the contour of an object, and a portion of the object was sometimes at the attended location. Thus, the subjects were judging a feature of an object that sometimes partly coincided with the locus of attention. If selective attention is object based, we might expect that judgments about the line segment would be enhanced by coincidence between the locus of attention and a portion of the object. Importantly, attention was first directed to an empty spatial location, so the initial selection could not be to an object or to a set of grouped locations defined by the object.

\section{Method}

Subjects. In return for elass credit, 10 undergraduates participated in a single, 1-h session. They all had normal or corrected-tonormal vision, were naive as to the purposes of the experiment, and had not served previously.

Apparatus, Stimuli, and Procedure. The sequence of events on each trial is illustrated in Figure 5. The subjects first saw a fixation display that consisted of a white fixation plus that subtended $0.5^{\circ} \times 0.5^{\circ}$, embedded in a mask that was composed of 50 randomly arranged lines drawn within a square area that subtended $3.0^{\circ} \times 3.0^{\circ}$. This display was presented for $400 \mathrm{msec}$, and then the mask was removed and either an exogenous or an endogenous cue was presented.

The exogenous cue consisted of a ring $0.75^{\circ}$ in diameter that was presented for $150 \mathrm{msec}$ at one of the four corners of an imaginary $2.0^{\circ} \times 2.0^{\circ}$ square that was centered within the $3.0^{\circ} \times 3.0^{\circ}$ square. The endogenous cue was a small arrow that subtended $0.4^{\circ} \times 0.4^{\circ}$ and was presented at fixation. The arrow replaced the fixation plus for $800 \mathrm{msec}$; the fixation plus was then restored when the arrow was removed.

After the cue was removed, a trapezoidal target object was displayed for $150 \mathrm{msec}$, as is shown in Figure 5. The mask was then redisplayed for $200 \mathrm{msec}$. Across all cue conditions, the object was equally likely to be displayed above, below, to the left, or to the right of the fixation plus. On one end of the object was a gap that subtended either $0.15^{\circ}$ or $0.25^{\circ}$. The subjects' task was to indicate whether the gap was large $\left(0.25^{\circ}\right)$ or small $\left(0.15^{\circ}\right)$ by pressing one of two keys. After the subjects responded or after the $1,000 \mathrm{msec}$ response period expired, the next trial began. The subjects were provided with performance feedback and an opportunity to take a short rest after every 64 trials.

The relative locations of the gap and the attentional cue could take one of several forms. In the cued condition, the gap was located at the cued location. In all other conditions, the gap was located at an uncued location. In the uncued attended-object condition, one end of the trapezoidal target object was located at the cued location, but the gap was at the other end of the object. In the uncued unattended-object condition, no part of the trapezoid was coincident with the cued location. Importantly, the location of the gap in the uncued attended-object condition was exactly the same as that in the uncued unattended-object condition, with the only difference between conditions being the fact that a portion of the ob- 


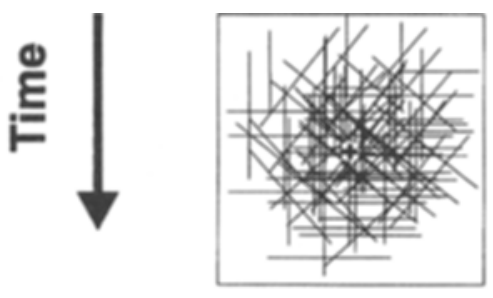

\section{Mask}
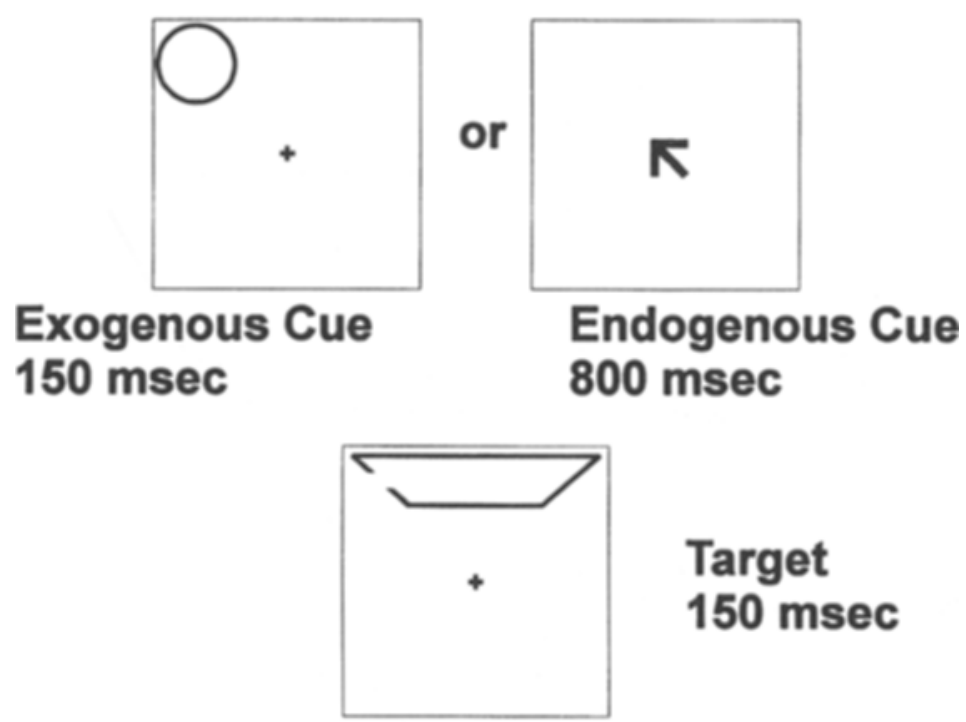

Target
150 msec

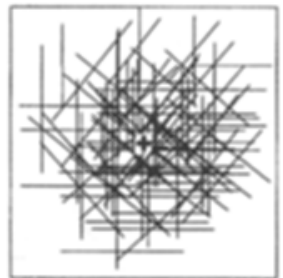

Mask

Figure 5. The sequence of events during a trial in Experiment 4. Note that the stimuli were gray against a black background and that a stylized interpretation of the mask is shown.

ject was coincident with the cued location in the former condition. In the uncued far condition, the gap was in the location on the display that was diagonally opposite to the cued location.

Design. At the beginning of each session, a practice block of 20 trials was presented; these trials were randomly selected from among the possible conditions. Four experimental blocks, each composed of 256 trials, followed the practice block. Of these 256 trials, $160(62.5 \%)$ were validly cued trials. Half of the trials were endogenous cue trials, and the other half were exogenous cue trials. For each cue type, an equal number of small and large gap trials was presented.

\section{Results}

Means of the median reaction times are shown in Figure 6 for each condition separately for exogenous (top panel) and endogenous (bottom panel) cues. There was a main effect of cue type, with discrimination judgments following endogenous cues being somewhat slower overall than those following exogenous cues $[F(1,9)=9.3$, $p<.05]$. There was also a main effect of condition $[F(3,27)=12.9, p<.001]$, but effects of condition and type of cue did not interact $[F(3,27)=1.7$, n.s. $]$.

The most important comparison is between the uncued attended-object and the uncued unattended-object conditions. To learn more about the object-based effect, we conducted another analysis of variance, involving only the results from those two conditions for the endogenous and exogenous cues (i.e., the conditions represented by the two middle bars in each panel of Figure 6). Latencies were faster under exogenous cuing than under endogenous cuing $[F(1,9)=8.8, p<.05]$. The subjects were also faster to judge the size of the gap in the uncued attended-object condition than in the uncued unattendedobject condition, showing a strong object-based effect in the present paradigm $[F(1,9)=17.9, p<.005]$. Although the size of the object effect was somewhat larger after exogenous cuing than after endogenous cuing, the dif- 


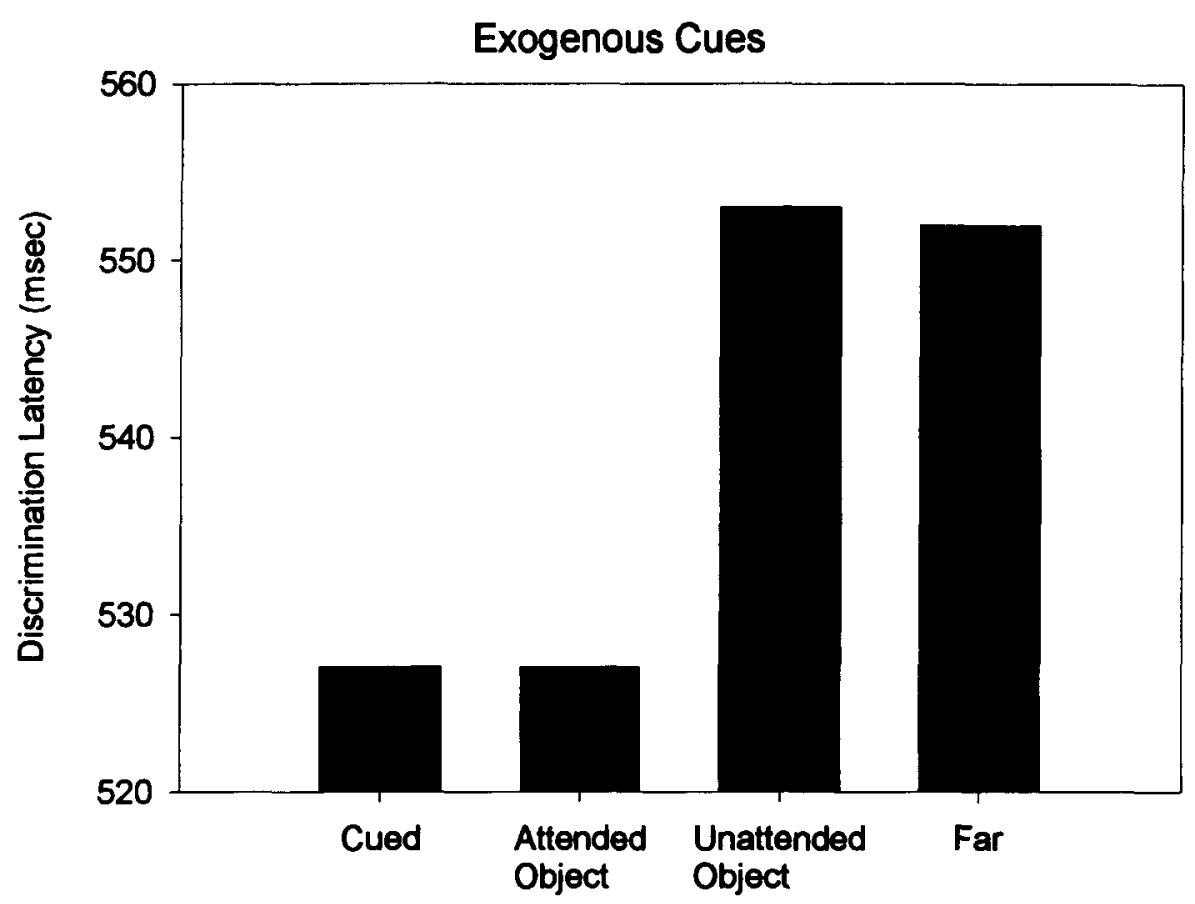

Cue-Target Relationship

\section{Endogenous Cues}

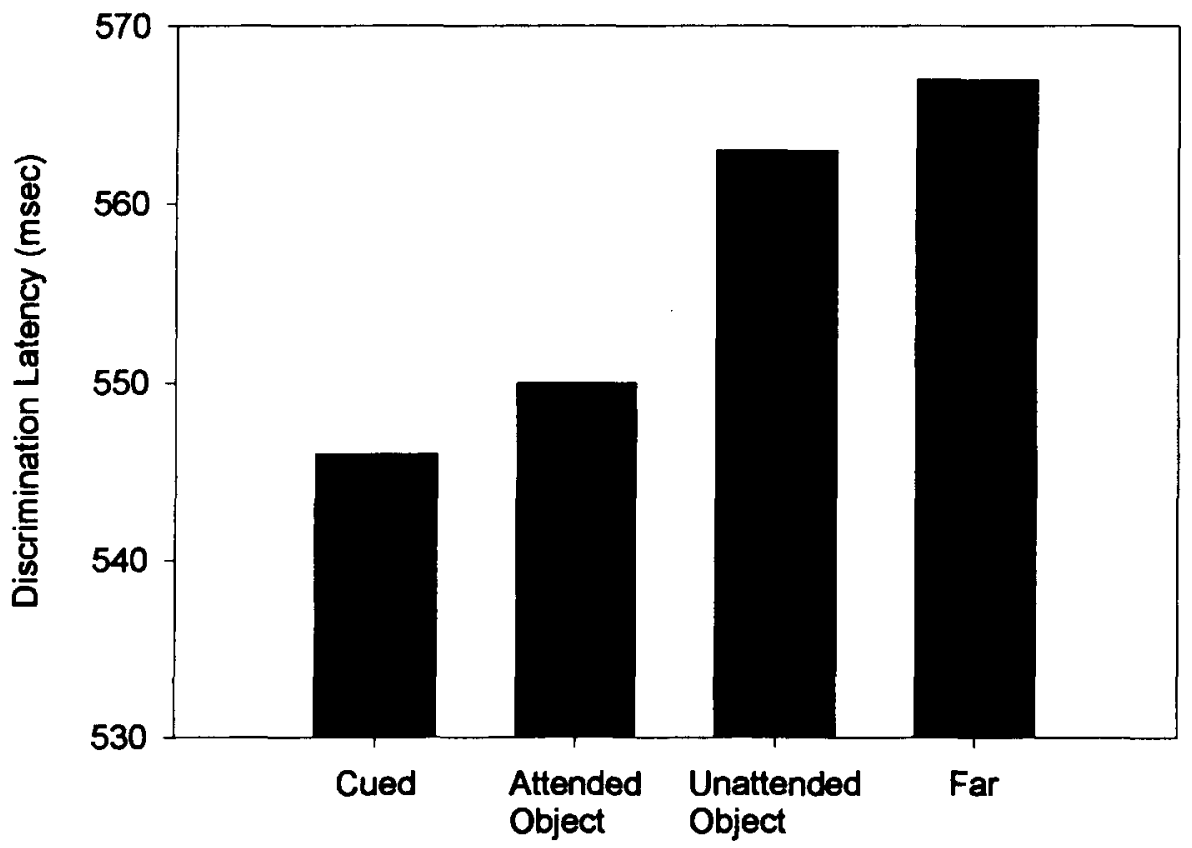

\section{Cue-Target Relationship}

Figure 6. Mean reaction times from Experiment 4. Faster latencies in the uncued attendedobject condition (designated "attended object" in the figure) than in the uncued unattendedobject condition ("unattended object") is evidence of an object advantage. 
ference (i.e., the interaction between type of cue and target location) was not reliable $[F(1,9)=3.1, p>.10]$. The subjects made errors on fewer than $1 \%$ of the trials, and the errors were not analyzed further.

\section{Discussion}

The present experiment extends the findings of objectbased selection with both exogenous and endogenous attentional cues to a new situation. Here, unlike in the previous experiments, the subjects moved their attention to an empty spatial location before they knew where the stimulus would appear. Thus, neither could they have been allocating attention to an object at that time, nor could they have directed their attention to a grouped array of locations that defined the object's contours. Nevertheless, when the stimulus did appear, there was an advantage if the object containing the discrimination target was spatially coincident with the location to which attention had been directed.

Notably, attentional selection was entirely object based with both exogenous and endogenous cuing. That is, the subjects were as fast at the uncued end of the attended object as they were when the discrimination target appeared at the cued location. [The 4.3-msec advantage at the cued location in the endogenous condition did not reach significance, $t(9)=1.1$, n.s.; the means for exogenous cues were within $1 \mathrm{msec}$ of each other.] Thus, there was no effect of proximity to the locus of attention. Instead, attention appears to have been allocated equally across the entire object when it appeared. This pattern differs from that obtained in Experiment 2, in which the subjects were fastest to detect the target at the cued location. We attribute the different pattern of results to the fact that, here, attention had already been directed to a spatial location prior to the appearance of the object, whereas the object was displayed in advance in Experiment 2. In the present experiment, when the new perceptual object appeared, it may have attracted attention in a manner similar to that which other researchers have identified (e.g., Oonk \& Abrams, 1998; Yantis \& Hillstrom, 1994). And apparently, attention was attracted equally to all parts of the object. It is important to note, however, that the new object captured attention only when it was at least partially spatially coincident with the attentional cue. Thus, these results may reveal the extent to which stimulus-driven mechanisms triggered by the appearance of a new object may interact with the effects of prior attentional cues and with expectancies regarding the likely location of an upcoming discrimination target.

It is also important to note that we obtained a result consistent with object-based radiation of attention in the present experiment, using a cue-target interval of $800 \mathrm{msec}$, although we failed to find such an effect in Experiment 2 with a similar cue-target interval $(900 \mathrm{msec})$. We attributed the absence of an effect in Experiment 2 to a type of inhibition of return that acted on the uncued end of the cued object after the attention that had radiated there had receded. No such phenomenon could take place in the present experiment, however, because here the ob- ject was not displayed until the end of the cue-target interval. Thus, during the cue-target interval, there was no object present through which attention and then, perhaps, inhibition of return could radiate. As a result, we were able to observe the object-based radiation of attention even at a long delay after the cue.

\section{EXPERIMENT 5}

We have shown, using three different paradigms, that endogenously oriented attention appears to make use of object representations, yielding the radiation-of-attention effect. This conclusion, however, is at odds with results reported by Macquistan (1997), Neely and Dagenbach (1996), and Dagenbach et al. (1997). On the surface, the methodology used in each of these previous experiments is very similar to that used in the present Experiment 2. However, in each of the earlier experiments, the subjects were exposed to only a single cue-target interval. In our Experiment 2, two intervals were used. Multiple cuetarget intervals would have the effect of increasing temporal uncertainty, and there is some reason to believe that changes in temporal uncertainty might modulate the object-based effect. For example, performance in the present task might be enhanced if a subject could narrowly focus his or her attention on the expected target location. Such narrowing of the attentional focus is presumed to be effortful, and hence, the subjects would be more likely to engage in such a process when they have more information about the approximate time of target presentation. Lavie and Driver (1996) have recently shown that a narrowing in the focus of attention eliminates objectbased attentional orienting (see also Laberge, Brown, Carter, Bash, \& Hartley, 1991, for a somewhat different narrowing of attention in response to temporal features of the stimuli). Presumably, as the subjects are more focused on a given location, they are less likely to use an objectbased representation to guide their orienting. Importantly, such an effect may have been occurring in the studies of Macquistan (1997) and Dagenbach and colleagues (Dagenbach et al., 1997; Neely \& Dagenbach, 1996) because they studied only one cue-target interval at any one time. Such an effect presumably did not occur in our Experiment 2 because we included two cue-target intervals there. To test this possibility, we conducted the present experiment. This experiment was identical to Experiment 2, with the only difference being that, here, we included only the 300 -msec cue-target interval.

\section{Method}

Subjects. In return for class credit, 15 undergraduates participated in a single, 1-h session. They all had normal or corrected-tonormal vision, were naive as to the purposes of the experiment, and had not served previously.

Apparatus, Stimuli, and Procedure. This experiment was identical to Experiment 2, with the exception that only a single cue-target SOA of $300 \mathrm{msec}$ was used here.

Design. At the beginning of each session, a practice block of 20 trials was presented, these trials were randomly selected from among the possible conditions. Three experimental blocks, each 

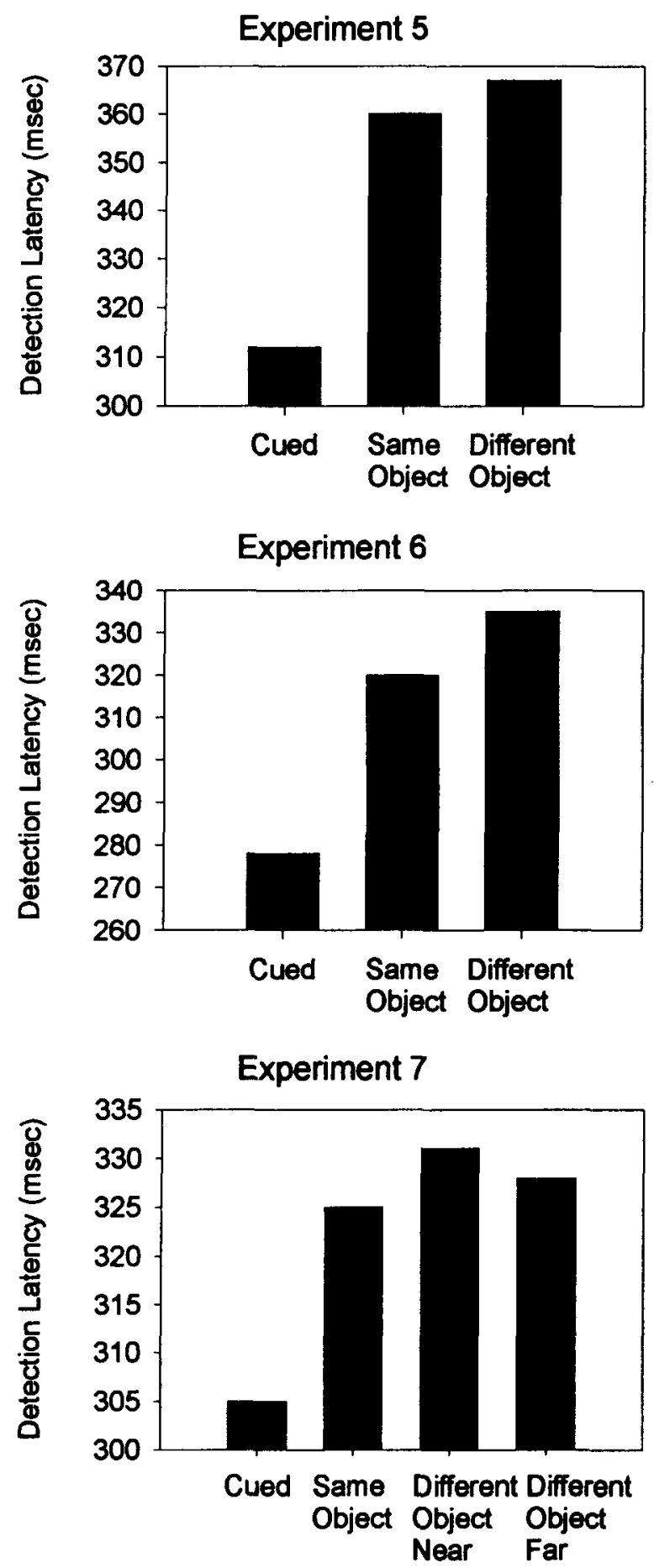

\section{Cue-Target Relationship}

Figure 7. Mean reaction times from Experiments 5, 6, and 7. An object advantage in Experiments 5 and 6 is shown by faster latencies in the uncued same-object condition (designated "same object" in the figure) than in the uncued different-object condition ("different object") and, in Experiment 7, is shown by faster latencies in the uncued same-object condition than in the uncued different-object near condition ("different object near"). composed of 144 trials, followed the practice block. Of these 144 trials, $32(22 \%)$ were catch trials. Of the trials that had targets, 80 were cued trials, 16 were uncued same-object trials, and 16 were uncued different-object trials.

\section{Results and Discussion}

Mean reaction times are presented in the top panel of Figure 7 separately for each of the conditions. The subjects were fastest in the cued condition, slower when the target appeared at an uncued location in the cued object, and slowest to respond to targets appearing in the uncued object $[F(2,28)=165.5, p<.001]$. A $t$ test confirmed a 7.2-msec object effect, with latencies on uncued sameobject trials faster than those on uncued different-object trials $[t(14)=2.2, p<.05]$. Thus, even with temporal certainty regarding the time of target presentation, we still found that endogenously cued targets are at least partly selected using an object-based representation, yielding the radiation-of-attention effect. Also, a comparison between Experiment 1 and the present results showed that the magnitude of the object effect was the same in the two experiments $[F(1,29)<1]$. Error trials were fewer than $2 \%$ of the total.

\section{EXPERIMENT 6}

One further difference between the experiments reported here and those conducted earlier by others (Dagenbach et al., 1997; Macquistan, 1997; Neely \& Dagenbach, 1996) is that we carefully monitored the subjects' eye positions and rejected any trials on which the subjects moved their eyes away from the central fixation point. Perhaps even more important, the subjects knew that careful fixation was required; otherwise, they would receive an error message. Because eye movements were constrained less formally in the previous work (Macquistan did not monitor subject's eye movements during the experiment and Neely and Dagenbach only monitored eye movements during practice trials), it is possible that the subjects in those studies produced eye movements in a manner that could account for the different pattern of results obtained. For example, if the subjects sometimes looked at the cued object but then returned their gaze to fixation, the eye movement might be expected to generate inhibition of return (Rafal et al., 1989). The inhibition could slow subjects in responding to targets on the cued object, thus offsetting a possible object-based facilitatory effect. Alternatively, the subjects may have simply fixated and concentrated on the cued location. Such focused selection might be expected to favor spacebased orienting and, thus, mask any object-based effects that might be more likely to occur during diffusely oriented attention (Lavie \& Driver, 1996).

We conducted the present experiment to examine the possibility that lax eye movement constraints may have caused the pattern of results observed by earlier researchers, in which there was no evidence of object- 
based orienting with endogenous cues. Here, we encouraged our subjects to make eye movements.

\section{Method}

Subjects. In return for class credit, 16 undergraduates participated in a single, 1 -h session. They all had normal or corrected-tonormal vision, were naive as to the purposes of the experiment, and had not served previously.

Apparatus, Stimuli, Procedure, and Design. This experiment was identical to Experiment 5, with the only exception being that we did not monitor eye position here. Instead, we suggested to the subjects that their performance would be better if they looked at the cued location.

\section{Results and Discussion}

Mean reaction times are shown in the middle panel of Figure 7, in which it can be seen that the subjects were fastest in the cued condition, slower in the uncued sameobject condition, and slowest in the uncued different object condition $[F(2,30)=132.7, p<.001]$. As in our other experiments, there was an object-based benefit: In this case, the subjects were $15 \mathrm{msec}$ faster to respond to targets at uncued locations on the cued object than to targets on the uncued object $[t(15)=5.67, p<.001]$. This result occurred here despite the encouragement we gave to the subjects to move their eyes. ${ }^{7}$ Thus, differences in eye movements that the subjects made do not seem to account for the different pattern of results obtained by us and by previous researchers who have examined endogenous orienting by using a similar paradigm (Dagenbach et al., 1997; Macquistan, 1997; Neely \& Dagenbach, 1996). The results help to further bolster the present findings and also allow us to be confident that the objectbased radiation of attention that we are observing with endogenous cuing does not depend on some unusual eye movement behavior. In addition, a comparison between Experiment 1 and these results showed that there was no difference in the magnitude of the object effect between the two experiments $[F(1,29)=1.2$, n.s. $]$. Error trials in the present experiment were fewer than $2 \%$ of the total.

\section{EXPERIMENT 7}

We consider here one final difference between our experiment and that of Macquistan (1997). In the experiments reported here (specifically Experiments 1, 2, 5, and 6), as in the Egly et al. (1994) study, on any given trial the target could appear in one of three possible locations: at either end of the cued rectangle or at one end of the uncued rectangle. Most important, the stimulus probabilities were such that the vast majority of the targets would appear in the cued object. For example, in Experiment 2, on trials in which a target was presented, the target appeared in the cued object $86 \%$ of the time. This feature of the design was due to a desire to present a highly valid cue, coupled with equal probabilities at each of the potential uncued target locations. Nevertheless, this may have caused the subjects to adopt a strategy in which they simply chose to attend to the cued object.
Such a strategy might be responsible for the object-based effects that we observed, rather than their being a more automatic consequence of orienting, as we have assumed. Importantly, the Macquistan study is not open to this criticism, because there the target was equally likely to appear in either the cued or the uncued object. To address this issue, in the present experiment, we adjusted the target probabilities so that the target was equally likely to appear in either the cued or the uncued object, while at the same time being most likely to appear at the cued location.

\section{Method}

Subjects. Fifteen undergraduates participated in a single, l-h session, for which they received a $\$ 5$ payment. They all had normal or corrected-to-normal vision, were naive as to the purposes of the experiment, and had not served previously.

Apparatus, Stimuli, and Procedure. This experiment was identical to Experiment 6, with the only exceptions being that we changed the target probabilities and instructed the subjects not to move their eyes from fixation. In the present experiment, the target appeared at the cued location $40 \%$ of the time (cued condition), at the uncued end of the cued object $10 \%$ of the time (uncued sameobject condition), and in each end of the uncued object $25 \%$ of the time (uncued different-object near and uncued different-object far conditions). Thus, the target was equally likely to appear in either the cued or the uncued object. Note that, in the previous experiments reported here, the target was not presented in the far end of the uncued object (i.e., furthest from the cued location), as it is here.

Design. After a practice block of 20 trials, the subjects completed three experimental blocks of 192 trials each. Of these 192 trials, 32 $(17 \%)$ were catch trials. Of the trials that had targets, 64 were cued trials, 16 were uncued same-object trials, 40 were uncued differentobject near trials, and 40 were uncued different-object far trials.

\section{Results and Discussion}

Means of the median reaction times are shown in the bottom panel of Figure 7, in which it can be seen that latencies depended on condition $[F(3,42)=22.3, p<.001]$. A $t$ test comparing uncued same-object and uncued different-object near conditions confirmed a $5.6-\mathrm{msec}$ object effect $[t(14)=3.29, p<.01]$. Latencies in the uncued different-object far condition did not differ from either of the other uncued conditions $[t s(14)<1.1]$. Error trials were fewer than $2 \%$ of the total.

The present results further bolster our earlier findings. We observed a benefit to detect targets at the uncued end of the cued object even when the target was equally likely to appear on either the cued or the uncued object. In addition, the target was 2.5 times more likely to appear in the near end of the uncued object, relative to the uncued end of the cued object; yet, the subjects were still faster to detect the target in the cued object.

\section{GENERAL DISCUSSION}

In the present experiments, the subjects were cued to attend to a particular spatial location in anticipation of the presentation of a subsequent target. The results from detection and discrimination judgments, using three different types of paradigms and under a range of temporal and spatial uncertainty, revealed that, under purely en- 
dogenous orienting conditions, the subjects' selective attention was based at least in part, on the objects present in the scene. The consequence of this was that the benefit of attention radiated through the cued object. These results add to the growing list of conditions under which object-based representations appear to play an important role in attentional selection.

\section{Endogenous Versus Exogenous Orienting}

Our results have important implications for an understanding of the mechanisms underlying endogenous and exogenous orienting. As was noted earlier, researchers have identified a number of differences between the mechanisms underlying endogenous and exogenous selection (e.g., Jonides, 1981; Klein, 1994; Müller \& Rabbitt, 1989). Despite the numerous differences between them, the present results show that both modes of orienting appear to rely on object-based representations. Thus, it is not necessary to posit distinct mechanisms or representations of space used for orienting by endogenous and exogenous systems. This interpretation is strengthened by the fact that cue condition did not interact with cue type in comparisons of the results from Experiment 1 with those from Experiments 2, 5, and 6. This is in contrast to the conclusions of Dagenbach et al. (1997), Neely and Dagenbach (1996), and Macquistan (1997). Those researchers failed to find any benefit accruing to uncued locations on cued objects when the cues were purely endogenous. Although we are not yet certain what can account for the discrepant results, we have ruled out differences in temporal and spatial certainty and in eye movement behavior. ${ }^{8}$ It is worth noting that the mean magnitude of the object effect across our five experiments that measured latencies under endogenous cuing was a somewhat small $9.1 \mathrm{msec}$. The size of the effect may have contributed to the difficulty that others have had in detecting it. ${ }^{9}$

\section{Attentional Spotlights and Gradients}

Our results, as well as those of Egly et al. (1994) and others, may also bear on work regarding the spatial structure of visual attention. Several researchers have described attention as a filter that can be represented by an activation gradient, with the peak of the gradient located at the focus of attention (Downing \& Pinker, 1985; Henderson \& Macquistan, 1993; Klein \& McCormick, 1989; LaBerge \& Brown, 1989; LaBerge, Carlson, Williams, \& Bunney, 1997; Shulman, Wilson, \& Sheehy, 1985; see also Logan, 1996). Our results are consistent with these conceptions, in the sense that the peak of the gradient is presumed to be at the cued location-the location with the quickest responses in all of our experiments. Furthermore, our results also suggest that such a gradient must be object aware, because uncued locations on the objects that had been cued were responded to more quickly than equidistant locations that were not on the cued object. One way in which this might happen is for the gradient to decline less steeply for locations that are part of the same perceptual group as the attended item but then to decline more steeply for other locations. Indeed, this is similar to a mechanism proposed by LaBerge and Brown. In their model, the peak of the gradient is scaled in space to match the expected target size. The new conclusion about these mechanisms that is now possible is that these concepts apparently apply to purely endogenously cued attention.

Our work can also be reconciled with conceptualizations of visual attention as a moving spotlight (Posner, Snyder, \& Davidson, 1980) or zoom lens (Eriksen \& Yeh, 1985). According to these views, attention has a limited spatial extent and must be moved from its current location when resources are needed to process a target elsewhere. Our findings, and other evidence supporting object-based orienting, suggest that the ease with which the attentional focus can be moved might depend on the extent to which it must cross an object boundary. More to the point, the present results show that the sensitivity to objects would apply not only to stimulus-driven (exogenously cued) attention, but also to goal-directed (endogenous) attention.

\section{Spatially Invariant Object Representations}

As was noted earlier, our results do not bear on the distinction between object-invariant representations and selection from grouped spatial arrays (Kramer et al., 1997; Vecera, 1997), nor were they intended to do so. Our results do show, however, that at least some type of objectbased selection does occur for purely endogenous orienting. Of course, it is possible that exogenous cues activate grouped arrays (as was found by Vecera, 1994), whereas endogenous orienting activates spatially invariant representations. And it may also be that the different types of representations are active simultaneously and interact with each other (Vecera, 1997). Additional work will be needed to resolve the issue.

\section{Relation to Previous Research}

The present results are consistent with a number of previous studies on the role of objects in attentional selection. Most notably, we replicated the radiation-ofattention result reported by Egly et al. (1994) with exogenous cues, and we extended the result to endogenous cuing. A number of other researchers have also demonstrated object-based selection under a variety of different conditions (see Kanwisher \& Driver, 1992, for a review). Taken together, the pattern of results indicates that the objects and, more generally, perceptual groupings that are present in a complex scene may provide an important structure that is used to guide selection from that scene.

There are also some ways in which our results differ somewhat from previous findings. In particular, Lavie and Driver (1996) reported that focusing attention to a portion of a scene eliminated the object advantage in their study, in which subjects judged attributes of dashed line segments. However, those are essentially the conditions under which our subjects oriented in all of our experiments, and we did observe a consistent object advantage. One important difference between the two paradigms is that the objects that we used were not spatially overlap- 
ping, unlike those of Lavie and Driver. As a result, any spatial narrowing of attention in our task would likely favor one of the objects, whereas that was not the case in Lavie and Driver's study. Note, however, that we did obtain an object advantage even when the stimulus was equally likely to appear in either of the two presented objects (Experiment 7).

\section{Locus of Object Effects}

It may also be possible to speculate somewhat about the locus of the object-based effects by considering the results involving temporal order judgments (Experiment 3 ). Stelmach and Herdman (1991) explained their temporal order findings by assuming that attention increased the speed of transmission of sensory information in the visual system. Information from attended locations was thought to arrive earlier at a temporal order comparator because of the increased transmission speed. In our experiment, the subjects judged events at the uncued end of the attended object to occur prior to simultaneous events on an uncued object. If the Stelmach and Herdman view is correct, our results suggest that information about perceptual objects may have an effect fairly early in the information-processing stream-at least prior to the temporal order comparator. An early locus for the effect of objects has also been reported in a different paradigm (Davis \& Driver, 1994).

\section{Conclusions}

The present results show that the object-based radiation of visual attention reported by Egly et al. (1994) under peripheral cuing conditions also occurs with purely endogenous cuing. This result helps to integrate exogenous and endogenous orienting, suggesting that a common representation may be used for the guidance of both types of selection.

\section{REFERENCES}

Abrams, R. A., \& DobKin, R. S. (1994). Inhibition of return: Effects of attentional cuing on eye movement latencies. Journal of Experimental Psychology: Human Perception \& Performance, 20, 467- 477.

Abrams, R. A., Oonk, H. M., \& PratT, J. (1998). Fixation point offsets facilitate endogenous saccades. Perception \& Psychophysics, 60 , 201-208.

BAYLIS, G. C., \& DRIVER, J. (1993). Visual attention and objects: Evidence for hierarchical coding of locations. Journal of Experimental Psychology: Human Perception \& Performance, 19, 451-470.

Briand, K. A., \& KLein, R. M. (1987). Is Posner's "beam" the same as Treisman's "glue"?: On the relation between visual orienting and feature integration theory. Journal of Experimental Psychology: Human Perception \& Performance, 13, 228-241.

Dagenbach, D., Goolsby, B., NeEly, C. A., \& Dudziak, K. M. (1997, November). Further studies of attention to space and objects with endogenous cuing. Poster presented at the 38th Annual Meeting of the Psychonomic Society, Philadelphia.

DAVIS, G., \& DRIVER, J. (1994). Parallel detection of Kanisza subjective figures in the human visual system. Nature, 371, 791-793.

Downing, C. J., \& Pinker, S. (1985). The spatial structure of visual attention. In M. I. Posner \& O. S. M. Marin (Eds.), Attention and Performance XI (pp. 171-187). Hillsdale NJ: Erlbaum.

DrIVER, J., \& BAYLIS, G. C. (1989). Movement and visual attention: The spotlight metaphor breaks down. Journal of Experimental Psychology: Human Perception \& Performance, 15, 448-456.

DUNCAN, J. (1984). Selective attention and the organization of visual information. Journal of Experimental Psychology: General, 113, 501-517.

EGLY, R., DRIVER, J., \& RAFAL, R. D. (1994). Shifting visual attention between objects and locations: Evidence from normal and parietal lesion subjects. Journal of Experimental Psychology: General, 123, 161-177.

ERIKSEN C. W., \& YeH, Y. (1985). Allocation of attention in the visual field. Journal of Experimental Psychology: Human Perception \& Performance, 11, 583-597.

Henderson, J. M., \& Macquistan, A. D. (1993). The spatial distribution of attention following an exogenous cue. Perception \& Psychophysics, 53, 221-230.

JONIDES, J. (1981). Voluntary vs. automatic control over the mind's eye's movement. In J. B. Long \& A. D. Baddeley (Eds.), Attention and performance $L X$ (pp. 187-203). Hillsdale, NJ: Erlbaum.

JoRDAN, H., \& TIPPER, S. P. (1999). Spread of inhibition across an object's surface. British Journal of Psychology, 90, 495-507.

Kahneman, D., Treisman, A., \& GibBs, B. J. (1992). The reviewing of object files: Object-specific integration of information. Cognitive Psychology, 24, 175-219.

KANWISHER, N., \& Driver, J. (1992). Objects, attributes, and visual attention: Which, what, and where. Current Directions in Psychological Science, 1, 26-31.

KLEIN, R. M. (1994). Perceptual-motor expectancies interact with covert visual orienting under conditions of endogenous but not exogenous control. Canadian Journal of Experimental Psychology, 48, 167-181.

KLEIN, R. M., \& HANSEN, E. (1990). Chronometric analysis of spotlight failure in endogenous visual orienting. Journal of Experimental Psychology: Human Perception \& Performance, 16, 790-801.

KLEIN, R. M., \& MCCormick, P. (1989). Covert visual orienting: Hemifield-activation can be mimicked by zoom lens and midlocation placement strategies. Acta Psychologica, 70, 235-250.

KRAMER, A. F., \& JACOBSON, A. (1991). Perceptual organization and focused attention: The role of objects and proximity in visual processing. Perception \& Psychophysics, 50, 267-284.

Kramer, A. F. Weber, T. A., \& WATSON, S. E. (1997). Object-based attentional selection-Grouped arrays or spatially invariant representations?: Comment on Vecera and Farah (1994). Journal of Experimental Psychology: General, 126, 3-13.

LABERGE, D., \& BROWN, V. (1989). Theory of attentional operations in shape identification. Psychological Review, 96, 101-124.

LaBerge, D., Brown, V., Carter, M., Bash, D., \& Hartley, A. (1991). Reducing the effects of adjacent distractors by narrowing attention. Journal of Experimental Psychology: Human Perception \& Performance, 17, 65-76.

LaBerge, D., Carlson, R. L., Williams, J. K., \& Bunney, B. G. (1997). Shifting attention in visual space: Tests of moving-spotlight models versus an activity distribution model. Journal of Experimental Psychology: Human Perception \& Performance, 23, 1380-1392.

LAVIE, N., \& DRIVER, J. (1996). On the spatial extent of attention in objectbased visual selection. Perception \& Psychophysics, 58, 1238-1251.

LaW, M. B., \& ABrams, R. A. (1997, November). Endogenous and exogenous control of object-based attention. Paper presented at the 38 th Annual Meeting of the Psychonomic Society, Philadelphia.

LAW, M. B., \& ABRAMS, R. A. (2000). Simultaneous facilitation and inhibition on the surface of an object. Manuscript submitted for publication.

LogAN, G. D. (1996). The CODE theory of visual attention: An integration of space-based and object-based attention. Psychological Review, 103, 603-649.

MACQUisTan, A. D. (1997). Object-based allocation of visual attention in response to exogenous, but not endogenous, spatial precues. Psychonomic Bulletin \& Review, 4, 512-515.

Müller, H. J., \& RABBITT, P. M. A. (1989). Reflexive and voluntary orienting of visual attention: Time course of activation and resistance to interruption. Journal of Experimental Psychology: Human Perception \& Performance, 15, 315-330.

MURPHY, K. R., \& MYORS, B. (1998). Statistical power analysis. A sim- 
ple and general model for traditional and modern hypothesis tests. Hillsdale, NJ: Erlbaum.

Neely, C. A., \& Dagenbach, D. (1996, October). Exogenous and endogenous cuing: Spatial versus object-based visual attention. Poster presented at the 37th Annual Meeting of the Psychonomic Society, Chicago.

Oonk, H. M., \& ABrams, R. A. (1998). New perceptual objects that capture attention produce inhibition of return. Psychonomic Bulletin \& Review, 5, 510-515.

PosNer, M. I. (1980). Orienting of attention. Quarterly Journal of Experimental Psychology, 32, 3-25.

PosNer, M. I., \& CoHEN, Y. (1984). Components of visual orienting. In H. Bouma \& D. G. Bowhuis (Eds.), Attention and performance $X$ : Control of language processes (pp. 531-556). Hillsdale, $\mathrm{NJ}$ : Erlbaum.

Posner, M. I., SNYDER, C. R., \& DAVIDSON, B. J. (1980). Attention and the detection of signals. Journal of Experimental Psychology: General, 109, 160-174.

Rafal, R. D., Calabresi, P. A., Brennan, C. W., \& Sciolto, T. K. (1989). Saccade preparation inhibits reorienting to recently attended locations. Journal of Experimental Psychology: Human Perception \& Performance, 15, 673-685.

RigGio, L., \& KirSNER, K. (1997). The relationship between central cues and peripheral cues in covert visual orienting. Perception \& Psychophysics, 59, 885-899.

Shulman, G. L., Wilson, J., \& Sheehy, J. B. (1985). Spatial determinants of the distribution of attention. Perception \& Psychophysics, 37, 59-65.

Stelmach, L. B., \& Herdman, C. M. (1991). Directed attention and perception of temporal order. Journal of Experimental Psychology: Human Perception \& Performance, 17, 539-550.

Tipper, S. P., Driver, J., \& Weaver, B. (1991). Object-centered inhibition of return of visual attention. Quarterly Journal of Experimental Psychology, 43A, 289-298.

VECERA, S. P. (1994). Grouped locations and object-based attention: Comment on Egly, Driver, and Rafal (1994). Journal of Experimental Psychology: General, 123, 316-320.

VECERA, S. P. (1997). Grouped arrays versus object-based representations: Reply to Kramer et al. (1997). Journal of Experimental Psychology: General, 126, 14-18.

VECERA, S. P., \& FARAH, M. J. (1994). Does visual attention select objects or locations? Journal of Experimental Psychology: General, 123, 146-160.

WOLFE, J. M. (1994). Guided Search 2.0: A revised model of visual search. Psychonomic Bulletin \& Review, 1, 202-238.

YANTIS, S. (1998). The control of visual attention. In H. Pashler (Ed.), Attention (pp. 223-256). London: University College London Press.

YANTIS, S., \& Hillstrom, A. P. (1994). Stimulus-driven attentional capture: Evidence from equiluminant visual objects. Journal of Experimental Psychology: Human Perception \& Performance, 20, 95-107.

YANTIS, S., \& JoNIDES, J. (1990). Abrupt visual onsets and selective attention: Voluntary vs. automatic allocation. Journal of Experimental Psychology: Human Perception \& Performance, 16, 121-134.

\section{NOTES}

1. We have also recently reported an important difference between endogenously and exogenously signaled eye movements: They differ with respect to the magnitude of the effect of prior fixation point offset (the gap effect; Abrams, Oonk, \& Pratt, 1998).

2. Vecera (1994) has argued that the Egly et al. (1994) results do not reflect true object-based selection per se but, rather, demonstrate selection from a special set of spatial locations. According to him, if attentional selection was based on a spatially invariant object representation, the Egly et al. effect should be independent of the distance between cued and uncued objects. Because that did not occur in Vecera's (1994) experiment, he concluded that selection in the Egly et al. task was made in a space-based representational system. In particular, the subjects are presumed to have selected the locations defined by the cued object's border. As a result, uncued locations on the cued object enjoyed an attentional advantage. For our present purposes, the distinction between a group of spatial locations and a spatially invariant object representation is not important. Our question regarding differences between endogenous and exogenous orienting would be important to answer in either case. Indeed, Kramer et al. (1997) characterized this distinction as one of two different models of object-based selection, which is also how we prefer to think of it. Also, see Logan (1996) for a theoretical approach that combines space-based and object-based representations.

3. It is worth noting that in Logan's (1996) model, grouping is accomplished only on the basis of proximity, so some additional extensions would need to be developed for it to account for performance in a task such as that of Egly et al. (1994).

4. We used rectangles oriented obliquely in this and several other experiments not reported here, because we wanted the potential target locations to be located along the vertical or the horizontal meridian. The orientation seems to make little difference, and this issue will not be pursued in the present paper. In Experiments 2, 5, 6, and 7, the rectangles were oriented as shown in Figure 1.

5 . We report analyses of the medians here and in each of the subsequent experiments. However, we also analyzed mean reaction times in each experiment. In all cases, the results involving means and medians were the same, with reliable differences always occurring for both measures of central tendency.

6. It is worth noting that the bias that we observed in temporal order judgments could possibly reflect a bias in the subjects' responses, and not necessarily a perceptual bias. Additional work would be needed to rule out that possibility, although such a bias would continue to reflect an object-based phenomenon, albeit a slightly different one than we are suggesting.

7. Note that we did not monitor the subjects' eye movements in this experiment, so we cannot be certain that they were consistently looking to the cued location. Nevertheless, informal observations reveal that the instruction to move the eyes to the cued location is very easy to follow.

8 . One additional factor that is probably not responsible for the different results obtained involves the subject's task in the various experiments. That is, we found evidence for radiation of attention after purely endogenous cuing in both detection (Experiments 2, 5, 6, and 7) and discrimination (Experiments 3 and 4) tasks. Macquistan (1997) studied discriminations, whereas Neely and Dagenbach (1996) and Dagenbach et al. (1997) used detection.

9. Despite the small size of the reaction time difference, a power analysis (using the technique of Murphy \& Myors, 1998) failed to support the possibility that differences in experimental power can explain the differences between our results and those of Macquistan (1997) and Neely and Dagenbach (1996). We did have reasonably high power in most of our experiments: The mean power was . 72 in each of our experiments involving endogenous cuing in which we observed object-based radiation of attention. But, the effect size was also quite large (mean = .46 , the proportion of the variance attributable to the experimental factor). Given the large effect size, both Macquistan (1997) and Neely and Dagenbach (1996) would have had sufficient power to detect it. In particular, assuming that power $=.8$ and alpha $=.05$, Neely and Dagenbach should have been able to detect an effect size equal to .36 , and Macquistan would have been able to detect an effect equal to .17 .

(Manuscript received June 30, 1998; revision accepted for publication May 11, 1999.) 